\title{
Letra de mão e escrita maquinal no fim da metafísica: arte, tecnologia e verdade no "Parmênides" de Heidegger"
}

Hand writing and mechanical typing at the end of Metaphysics:
Art, Technology and truth in Heidegger's "Parmenides"

Ms. Ione Manzali

iomanz@yahoo.com

PUC-RJ

A tão valorizada eficiência técnica da máquina de escrever foi questionada por Martin Heidegger ao contrasta-la com a escrita cursiva feita pela mão, que aponta como mais a própria do ser humano, em certos textos de sua segunda fase, incluindo a preleção "Parmênides" de 1942-43, que comentarei. A essência da verdade da escritura técnica, no âmbito da relação entre arte e técnica inserida numa história da metafísica producionista e esta, por sua vez, desdobrada da história do ser, será objeto de considerações.

PALAVRAS-CHAVE

Heidegger; Obra de arte; Fenomenologia; Verdade; Caligrafia; Tecnologia

Martin Heidegger, in a number of essays of his second phase, including the lecture "Parmenides" of 1942-43, that will be commented here, questions the glorification of the typewriter efficiency while contrasting it to the tradicional handwriting, pointed by him as man's proper and most appropriated form of writing. The essence of the truth of the technical writing, in the domain of the relation betwen art and technique which belongs to a history of productionist metaphysics which itself unfolds of the history of being, will be object of considerations.

KEY-WORDS Heidegger; Work of art. Phenomenology; Truth; 
A máquina de escrever, hoje obsoleta, era um importante objeto high-tech na época que Heidegger a problematizou. A tão valorizada eficiência técnica da máquina foi por ele questionada e contrastada com a escrita feita pela mão, que aponta como mais a própria do ser humano, em certos textos de sua segunda fase, incluindo a preleção inicialmente denominada "Parmênides e Heráclito" e mais tarde simplesmente "Parmênides" [GA 54], do semestre de inverno de 1942-43, e somente publicada postumamente em 1982, que comentarei.

Concentrando-se na interpretação do poema didático de Parmênides, Heidegger minuciosamente investiga o sentido primordial da relação entre ser e verdade ao empreender um retorno fenomenológico ao dizer original do poema, que mostra ser um poema-doutrina, e desconstruindo, neste movimento, o sentido atribuído a esta relação pela tradição metafísica. A questão da verdade e do ser, em torno da qual Heidegger desenvolveu toda a sua filosofia, reaparece aqui em meio à sua meditação da história do ser enquanto pensamento da essencialidade do ser da época moderna, que denominou Gestell, palavra tradicionalmente associada na língua alemã à armação, esqueleto ou estrutura, mas hifenizada e ressignificada por Heidegger como com-posição ou arrazoamento. A Gestell seria a verdade do mundo comandado pelo paradigma da tecnociência que, originado na filosofia platônico-socrática, impera desde a época moderna estendendo-se, com crescente de-finição, na contemporaneidade.

A deusa verdade é tematizada, no que nota Heidegger ser a verdade ela mesma a deusa, ao contrário da tradicional tradução como "deusa da verdade", querendo ele com isto dizer, a verdade sendo experienciada como deusa, i.e., o lugar do lógos histórico, e não como alegoria ou hipostasia de um conceito abstrato e geral. A palavra grega para verdade, alétheia, que foi por Heidegger anteriormente associada a desocultamento [Unverborgenheit] é, nos textos desta época, traduzida por desabrigo [Entbergen] e aqui se associa à ideia de um "des-esconder", significado em enthehlen, palavra do antigo alemão Hehlen, que remete a caverna ou esconderijo, onde o que protege e esconde se mostra enquanto abrigo e como ocultamento:

A antiga língua alemã conhecia até mesmo a palavra - que desde então se tem perdido - tirar fora do ocultamento [enthehlen]. Desde muitos anos uso nas preleções a palavra "descobrir" [entbergen]. Caso consigamos um dia de novo experimentar a pura abertura do descobrir [Entbergung] e a essência do desencobrimento [Unver- 
borgenheit], a alétheia, poderemos encontrar de novo a palavra perdida "desocultar" [enthelen] e nos apropriar dela de modo novo. Ocultar [hehlen] é, no mais, uma palavra relacionada proximamente com caverna [Höle], a qual encobre algo enquanto ela mesma permanece descoberta (HEIDEGGER, 2008 p.62).

Ao relevar o problema da verdade como da ordem do desabrigo e do desocultamento, Heidegger contraria a tradição ocidental de pensamento que toma esta palavra substancializada como um valor positivo, o fundamento estabilizado que se oporia à uma igualmente substancializada não-verdade, as Doxas, palavra grega traduzida comumente por opinião, e que desde a dominância da escola de Platão, consideradas de natureza instável e múltipla, e por isto, negativa. Vale lembrar que, desde Ser e Tempo, o caminho da incerteza e da impermanência foi mostrado como o mais originário, pois que fundado na finitude humana.

A verdade havia sido em Ser e Tempo localizada no Dasein. Entendida como descobrimento, alétheia, a verdade é mostrada ali como o antecede e que possibilita a verdade proposicional, a correspondência e a adequação de algo com algo. Em escritos de sua segunda fase, Heidegger muda a sua noção de verdade, sempre guiado pelo sentido de desencobrimento da alétheia. Reflete então sobre "a verdade do ser", da correspondência ao ser no abandono ek-sistente do Dasein ao que é, ao deixar-ser [Seinlassen].

Ainda neste âmbito de verdade, aqui no "Parmênides" Heidegger ocupou-se de mostrar a predominância do binarismo verdade e não-verdade que caracterizou a época romana e cristã e seus desdobramentos na metafísica ocidental. Mostra ali que haveria não apenas uma, mas várias formas de não-verdade enquanto dissimulação e ocultamento. Para se apreender, portanto, mais propriamente a essência da verdade da alétheia haveria que se pensar a sua contra-essência, o falso enquanto Pseudos. Ele nos mostra agora no "Parmênides", que o que se opõe mais originalmente à alétheia. No alemão, Wahrheit, não seria a impermanência e a incertitude das opiniões Dóxicas, mas o encoberto do dissimular, o falso, o Pseûdos ${ }^{1}$. Para os gregos, diz Heidegger, o oposto do Tó Alethés, o desencoberto, seria o Tó Pseudos, o falso enquanto encobrimento e encoberto, e não Léthe, que significaria o esquecimento e que seria da ordem

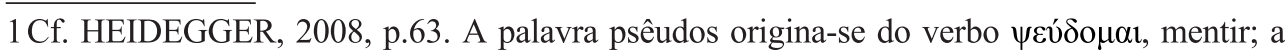
Doxa foi tematizada principlamente em Platão no diálogo "o sofista", e à seguir, em Aristóteles e Simplícius. 
do silêncio da fala, onde, "Pseûdos não caracteriza, somente, comportamento humano, (mas) é, muitas vezes, usado na referência ao Epos, Mythos e Legéin, à palavra e à linguagem." (HEIDEGGER, 2008, p.63). Em passagens de Homero que ele nos diz, há a equivalência entre apseudés, o não-dissimulado, o não-recolhido e aléthés ${ }^{2}$.

Heidegger expõe o caráter múltiplo do Pseûdos, sua ação de encobrir que é o dissimular que desfigura, e principalmente, mostra que a dissimulação enquanto o ocultamento de Psê̂dos é, acima de tudo, um sinal, Sêma (HEIDEGGER, 2008, p. 62).

E o que sinalizaria este sinal? Psê̂dos sinaliza o que não se mostra em seu mostrar, i.e., tanto aquilo que não se manifesta, o encoberto, quanto o próprio caráter encobridor do manifestado. O sinal encobre ao mesmo tempo em que indica o que ele se refere, é "um encobrir que aparece", diz Heidegger, acrescentando: "A apresentação de um sinal que mostra e, com isso, o próprio mostrar, são pseûdos. O encobrimento é um deslocar. O significado fundamental condutor de Pseûdos consiste em deslocar [Verstellen]" (HEIDEGGER, 2008, p.55).

O encoberto e o descoberto estariam assim associados em um "Da", um "aberto", i.e., um horizonte histórico de sentido aberto pela temporalização ek-stática do Dasein humano em sua correspondência ao ser, como afirma à seguir.

\begin{abstract}
Morte, noite, dia, luz, a terra, o subterrestre, o supraterrestre são atravessados pelo desencobrimento e pelo encobrimento e permanecem sob a mira dessa essência. Em toda parte vige primordialmente a ação de emergir em direção ao desencoberto e de afundar para dentro do encobrimento (HEIDEGGER, 2008, p.102).
\end{abstract}

A noção de verdade como desvelamento característica da alétheia é transformada na passagem para uma compreensão segundo o modo de ser latino, com a ascendência do império romano. A verdade como alétheia é então esquecida e a verdade como Veritas, que Heidegger mostra estar baseada na noção de adequação entre a coisa que presumidamente "é" e a sua representação mental, passa a vigorar. Para o filósofo, esta nova compreensão da verdade do se é o que

2HEIDEGGER, 2008, p. 40. “... terminologicamente, o corte do alfa conduz para léthes. Mas não encontramos esta palavra em nenhuma parte como o nome para indicar o falso. Este significa, antes, para os gregos, Tó Pseudos. “ 
marca o acontecimento de uma nova época da história, onde, a "História 'é' a transformação da essência da verdade. Entes históricos recebem seu ser de tal transformação" (HEIDEGGER, 2008, p.85).

Esta essência da história, pensada como o fundamento e a essência do próprio ser, é o que ele quer dizer, em seguida, quando afirma que acontecimento e história significam destino e "destinação" no sentido que:

Acontecimento [Geshehen] e história ['die' Geschichte] dizem: destino, destinação, envio. Genuinamente formulado em alemão, não falamos "de" história como "transcorrência", mas "de destinação", no sentido do destinar-se do ser (HEIDEGGER, 2008, p.85).

A Veritas romana teve, segundo Heidegger, a sua origem como a contraessência da palavra Falsum, o falso, cuja raiz Fallere abriga o sentido de fazer cair, derrubar e manipular para a dominação. Este sentido de verdade e de falso fundamentam o projeto imperial romano no ato imperial da constante sobrelevação por cima dos outros, os povos conquistados.

O âmbito de essência decisivo para o desenvolvimento do falsum romano é o do "império" do "imperial". Tomaremos essas palavras no seu sentido estrito e original. Imperium significa comando [...] no sentido do mandamento. O comando, assim entendido, é a razão essencial da dominação, não apenas sua consequência e, decerto, não simplesmente um modo de exercitar a dominação [...] o Deus do Antigo Testamento é um deus comandante. Sua palavra é "não deves", "deves". [...] Nenhum deus dos gregos é um deus "comandante", mas um deus que dá sinais, acena. Os deuses romanos, ao contrário, são designados pela palavra latina numen, que significa "ordem", "vontade" e têm um caráter de comando (HEIDEGGER, 2008, p. 66). 
Heidegger nos mostra, assim, que o decisivo que inaugura uma nova época se deu na latinização que transforma e transpõe [übergesetzt $]$ o psê̂dos grego para o falsum romano, movimento este que falsifica e oculta as suas distâncias e diferenças, além de sua própria ocorrência enquanto tradução.

A dogmática eclesiástica da fé cristã acentuou a tendência consolidante da essência da verdade enquanto Veritas no sentido da retidão, onde o verdadeiro torna-se o assegurado e o certo. O que é reto tem por necessidade ajustar-se ao real, devendo portanto expressar aquilo que o real diz e é. Isto, diz o filósofo, é a vontade de poder e a esta vontade de poder toda correção deverá conformar-se. Esta conformação é a justiça [iustitia] e a retidão [rectitudo], " $A$ Veritas romana se tornou a 'justiça' da vontade de poder" (HEIDEGGER, 2008, p.83).

Este abandono da essência da verdade enquanto alétheia marcaria, segundo Heidegger, o início da metafísica moderna ${ }^{3}$, e seria com a filosofia de Nietzsche que, no fim da metafísica ocidental, a verdade que passou do verum como certum imperial-civil para o verum como adequatium imperial-eclesiástico, recebe o acabamento da sua essência, onde a estrutura mais básica da realidade é a própria vida enquanto vontade de poder, como diz: “[...] O círculo da história da essência da verdade, experimentada metafisicamente, agora se fechou" (HEIDEGGER, 2008, p.83).

Assim, Heidegger reflete sobre o projeto metafísico que, segundo ele, iniciara-se a partir de certa interpretação da sentença de Parmênides sobre a verdade e se completa na modernidade tardia. Heidegger vê na filosofia de Nietzsche o anúncio da "completude", i.e., do acabamento e finalização deste projeto ocidental que não mais tem a ver com a alétheia e sim, agora, com a verdade da técnica. Investigando o que comanda os comandos do ente técnico, Heidegger quer mostrar a técnica de maneira mais originária, perguntando não pela técnica, mas pela essência da técnica. A Ge-stell, termo do alemão corrente, por ele hifenado e ressignificado, traduzido por com-posição e arrazoamento, seria a verdade da técnica, o modo de ser da modernidade tardia. A técnica não seria, pois, um instrumento a serviço do homem, mas uma forma de desencobrimento, uma determinada correspondência entre ser e homem que nos orienta os pensamentos e as ações.

Considerando-se a técnica um destino e uma destinação, porque a objeção de Heidegger à máquina de escrever? E o que teria o poema de Parmênides com isto? Diznos à seguir o filósofo:

3 HEIDEGGER, 2008: "[...] o estado histórico de mundo, que chamamos de idade moderna, seguindo a cronologia historiográfica, está fundado no evento da latinização da Grécia". 
Meu tema era a moderna relação (transformada pela máquina de escrever) da mão com a escrita, isto é, com a palavra, ou seja, com o desencobrimento do ser. Uma meditação acerca do desencobrimento e acerca do ser tem, naturalmente, tudo, não somente algo, a ver com o poema doutrinário de Parmênides (HEIDEGGER, 2008, p.126).

Para entender este questionamento ao modo técnico de registrar a palavra, devemos voltar à fenomenologia-hermenêutica da manualidade utensiliar, desenvolvida em "Ser Tempo". Neste tratado de 1927, Heidegger estabelece a primazia da coisa à mão [das Zuhandene], marcada pela sua relacionalidade com o agir humano mais básico que confronta com a noção do meramente presente [das Vorhandene], o objeto neutro e isolado, pressuposto pela ciência. Lembrando que mundo, em "Ser Tempo", é uma região ontológica anterior à noção comum de espaço e à relação sujeito-objeto, o mundo, o aí, o $D a$, é, ali mostrado como inseparável do Dasein, o ser do aí, o homem compreendido com ser-no-mundo. O desvelamento do ser nada mais é que o cumprimento do fenômeno do $D a$ e a primeira e última condição humana, antecedendo a tradicional noção do sujeito auto consciente. O Dasein não está, portanto, dentro de um mundo tanto quanto não se encontra apartado e inserido em um corpo porque em nenhuma instância, em nenhum instante, haveria a separação destes, não sendo então possível o pensamento fora do mundo, nem apartado de relações intramundanas. Não há, diz Heidegger, pensamento puramente cerebral e se algum setor do corpo seria privilegiado quanto ao ato de pensar, não seria o cérebro, mas as mãos. As mãos pensam porque nelas se concentra o fazer engajado pré-reflexivo com o mundo ambiente. Este fazer-engajado, que é associado em "Ser e Tempo" com a ideia de artesanato e utensílio, vai ser estendido para o próprio pensar. Pensar, portanto, para Heidegger, é um trabalho manual.

No texto de seu "Parmênides", o filósofo retorna à questão da mão, associando mão, ação, pensamento, linguagem e lógica (HEIDEGGER, 2008, p.80):

A mão existe como mão somente onde há desencobrimento e encobrimento. [...] A mão irrompeu somente da palavra e com a palavra. O homem não "tem" mãos, porém a mão se atém à essência do homem, porque a palavra, como o âmbito essencial da mão, é o funda- 
mento da essência do homem. [...] A palavra que se deixa cunhar e assim se mostra ao olhar, é a palavra escrita, isto é, a escrita. Mas a palavra como a escrita é a escrita à mão (HEIDEGGER, 2008, pp. 119-120).

A mão, tomada desta maneira como a medida de uma relação propriamente humana com as coisas do mundo, é, assim, no modo de ser do utensílio onde as coisas são inseparáveis de sua utilização por nós. Heidegger resgata para esta noção a palavra grega Pragma, traduzida comumente por res, coisa, mas por ele associada à ação, que diferencia de Práxis, o “em si” de uma atividade. É na mão humana que Heidegger localiza a essência do Pragma.

Pragma não significa nem a coisa por si nem a atividade por si [práxis]. Tá pragmata é aqui, antes, a palavra para dizer uma totalidade originariamente inseparável da relação entre coisas e homem. Traduzimos pragma por "ação" [Handlung]. Essa palavra, no entanto, não significa a atividade humana [actio], mas o caminho unitário com o qual, cada vez, as coisas estão presentes e disponíveis à mão, isto é, estão relacionadas com a mão (HEIDEGGER, 2008, pps. 124).

A noção de Pragma é esclarecida na ligação inseparável entre pragma e praxis: "Pragma aqui não é distinto e colocado à parte, separado como coisa e fato da práxis como presumida 'atividade" (HEIDEGGER, 2008, p.119) e que age, é, assim, a mão, mantendo no seu cuidado o agir o que é agido e o que é manipulado. "O homem, ele mesmo, 'age' através da mão; pois a mão é, junto com a palavra, a distinção essencial do homem. Somente um ente que, como ele, 'tem' a palavra [mythos, lógos], pode e necessita 'ter' 'a mão”' (HEIDEGGER, 2008, p.119).

Estaria, deste modo, na mão, a essência da relação recíproca entre homem e ente, os tá onta, as coisas, precisamente porque: “Há 'mão' somente onde os entes como tais aparecem como descobertos e o homem se comporta com os entes de modo desvelante. A mão sustenta, imediatamente, na palavra, a relação do ser com o homem" (HEIDEGGER, 2008, p.125). 
E qual seria então o problema da máquina de escrever? Afinal, não é com as mãos que se datilografa e se digita? Para Heidegger, a máquina de escrever obscurece tanto a mão quanto a escrita, e é, pois, justamente na sua verdade, o que a máquina de escrever é, no que ela revela e encobre, que reside o problema. Diz-nos o filósofo, então:

A máquina de escrever encobre a essência do escrever e da escrita. Ela subtrai ao homem a dignidade essencial da mão, sem que o homem experimente apropriadamente essa subtração e sem que reconheça que aqui se deu uma transformação da relação do ser com a essência de si mesmo (HEIDEGGER, 2008, p.126).

A máquina de escrever seria, então, uma "nuvem sem sinal", i.e., um encobrimento dissimulador". Teríamos, assim, saído da relação entre mão e "utensílio, instrumento e ferramenta", retirando a escrita a sua origem essencial, localizada por Heidegger na mão, e a transferido para o domínio do maquinal.

Se na máquina de escrever o que aparece é a máquina e não mais a mão e a ação envolvida com o utensílio, Heidegger caracteriza-a como uma "coisa intermediária" entre a ferramenta e a máquina, que chama de mecanismo (HEIDEGGER, 2008, p.127). A máquina de escrever não seria, então, apenas mais um aparelho, mas o mecanismo do encobrimento da escrita humana pelo maquinal da técnica, justamente porque a escrita humana não é apenas uma das tantas regiões do fazer humano, mas o próprio aí do humano, na sua íntima ligação com a essência da linguagem.

A máquina de escrever arranca a escrita do âmbito essencial da mão, e isto significa, da palavra. Esta se torna algo "datilografado"s. [...] A escrita mecânica priva a mão de seu valor próprio no âmbito da palavra escrita e degrada a palavra à um meio de comunicação. Além disso, o escrito à máquina oferece a "vantagem" de que nela se esconde a escrita à mão e com isso o caráter. $\mathrm{Na}$ escrita à máquina todos os homens parecem iguais (HEIDEGGER, 2008, p.120).

4A expressão é de Píndaro. Cf. HEIDEGGER, 2008, p.126.

5 A tradução norte-americana utiliza "tipado", que preserva a relação entre Typos e escrita como em typewriter. 
Mas, ainda assim, considerando-se que o lápis e a caneta, inserem-se já em uma história da técnica, é de se perguntar se Heidegger ao se opor à letra impressa não estaria se colocando contra a técnica pós séc. XV e a imprensa, o que o colocaria numa posição ultraconservadora e ingênua. Ou será que esta máquina representa algo distinto da máquina de imprimir de Guttenberg e das modernas impressoras de livros? O que mais ainda haveria de específico na máquina de escrever, para Heidegger?

É de se observar que a máquina de escrever, inicialmente mecânica e em seguida eletromecânica, foi substituída pelo processador de texto e pelo computador pessoal, e que este, desde então, tem-se tornado mais portátil e mais pessoal. Heidegger toca neste ponto ao diferenciar a transposição do escrito artesanal para a impressão em larga escala para o que ele vê nesta máquina tornada mecanismo. A história ao modo historiológico dos meios de escrita, é claramente localizada por Heidegger como a origem do que chama "a crescente destruição da palavra". Na passagem da arte da caligrafia para a técnica da datilografia residiria um anúncio decisivo da radicalização da impessoalidade transfigurada em individualismo no fim da escrita da era humanista. Não mais desenhamos letras, e são cada vez mais raros os artistas plásticos que sabem desenhar ou pegar num pincel, mas vê-se por toda parte uma dedicação incessante ao aperfeiçoamento da impessoalidade de cunho universalista desta escrita técnica. Imprimirmos um esforço uniforme previsível sobre tipos pré-formatados, adequando-nos ao movimento repetitivo da forma do mecanismo, onde o que se mostra acima de qualquer conteúdo, como diz Heidegger, é o modo técnico da própria técnica.

A escrita manual pode agora estar se transformando em um tipo de arte visual, dando prosseguimento à tradição da caligrafia isolada como uma forma das artes dos passatempos, restrita ao decorativo e ao ocasional. Pode ainda se tornar uma relíquia indecifrável para a maioria dos humanos e, tal os hieróglifos hoje, seria acessível apenas como especialização de uma diminuta parcela da população ${ }^{6}$. A letra artesanal com a marca da manualidade do humano, que, segundo Heidegger traz em si uma determinada essência do ser do humano, mostra inequívocos sinais de estar a caminho do encobrimento do esquecimento.

6É de se notar a paradigmática resolução recente do National Common Core State Standards, que determina o currículo escolar fundamental, adotada pela maior parte dos estados norte-americanos, que abole a obrigatoriedade do ensino de letra cursiva na educação primária em favor de uma orientação da educação infantil no treinamento da datilografia maquinal com ênfase na pesquisa por meio da internet. Não é de todo exagerado concluir que novas gerações que não mais aprendem a escrever à mão não serão capazes do deciframento da escrita cursiva. Considerando-se o avanço das transmissões orais, e.g. os sistemas de comando de voz substituindo a escrita nos tablets e smartphones, não seria impossível que, talvez até em pouco tempo, a maior parte dos humanos não disponha da capacidade da escrita nem da leitura, o que configuraria uma era marcada pela predominância do analfabetismo. Cf. http://www.corestandards. org/in-the-states. Acessado em 27/03/2012, 10:27 AM no Site http://www.corestandards.org/ 
No final de seu "Parmênides", Heidegger reflete sobre o esquecimento das palavras essenciais, onde esquecer a palavra equivaleria esquecer a origem de um projeto, neste caso, o nosso projeto coletivo humanista ${ }^{7}$. A reflexão sobre a história da escrita e seus efeitos teve já em Platão uma associação entre escritura e morte. No diálogo Phedro, através do mito de Theuth, Platão mostra na escrita um pharmakon que enquanto preserva, ao mesmo tempo destrói a memória. Heidegger retorna ainda à palavra léthe, que, diferentemente do pseûdos, o inevitável e constitutivo esquecer do encobrimento que mostra seu ocultar, seria um igualmente inevitável e constitutivo encobrimento, mas da ordem do lanthanestai ${ }^{8}$, o "esquecer", que Heidegger mostra ser o "esquecer do esquecimento", o velamento que não se confunde com um esquecimento casual no âmbito da consciência individual do sujeito moderno. A latência do autoencobrir-se da léthe seria o que vige nas certezas absolutas dos procedimentos técnicos ${ }^{9}$.

O que pode então morrer agora junto com a escrita caligráfica, e até com a escrita de sinais gráficos em geral, considerando se a escrita técnica também estiver rapidamente dando lugar a transmissões majoritariamente orais, é ainda desconhecido e encontra-se no centro da crise do humanismo, por sua vez enraizado na terra do entardecer e do poente [Abend-land], i.e., o ocidente, que para ele é a Europa.

Viver radicalmente esta crise do humanismo na era da técnica total e global significa para Heidegger, não a condenação da técnica das máquinas em busca de um passado idealizado, mas a escuta do apelo do Ge-stell, a essência da técnica, por ele vista como a abertura do novo para o novo, do inimaginável de uma nova era que se mostra em bases "pós-literárias, pós-epistolares e, portanto, pós-humanísticas"10. A recepção deste envio, segundo Heidegger, não se iguala à passividade dos indiferentes e ignorantes, mas seria, antes, ganha serenamente na "luta incessante"11 contra supostas verdades eternas das autori-

7 Apontando para as novas bases de coexistência das pessoas nas sociedades atuais, Peter Sloterdijk, num ensaio que denomina "Uma resposta a Carta sobre o Humanismo, de Heidegger", reflete sobre a "natureza humana", especulando sobre a caracterização de uma nova época, marcada pelo fim da escrita. Localiza estas novas bases na afluência da cultura de massa das mídias do radio e da televisão desde o fim da guerra, radicalmente atualizada na revolução da conexão planetária pela rede da internet, Sloterdijk especula as novas sínteses políticas e culturais que ocorrerão em bases “[...] pós-literárias, pós-epistolares e, portanto, pós-humanísticas, onde a transmissão escrita entre pessoas e povos ocorrerá, quando muito, de forma marginal” (SLOTERDIJK, 2000).

8 HEIDEGGER, 2008, p.107: o verbo Lanthanestai, que é traduzido usualmente por esquecer.

9 HEIDEGGER, 2008, p.107: “O esquecido é, na experiência dos gregos, o que afundou num encobrimento (numa latência)".

10 SLOTERDIJK, 2000.

11 A palavra luta em Heidegger refere-se ao Agon grego no sentido de uma relação que define identidade e diferença essencial e jamais se confunde com uma chamada para a mobilização 
dades, dos especialistas, das igrejas, dos sindicatos, dos partidos políticos e de outras nuvens sem sinal, que encobrem seu próprio escurecer.

Desta maneira, ao falar da máquina de escrever em seu "Parmênides", Heidegger aponta a saga ocidental que diz o começo essencial, colocando, assim, a questão do fim da metafísica. A ligação entre ser e verdade, desencobrimento, esquecimento e dissimulação, fica, assim, mostrada no âmbito da hermenêutica heideggeriana do acontecimento-apropriativo, caracterizada aqui por suas concepções do espaço-tempo e da arte-técnica da era da técnica que essencializa a modernidade tardia. A relação entre obra de arte, verdade e acontecimento-apropriativo que desde A Origem da Obra de Arte foi estabelecida por Heidegger $^{12}$, reaparece no texto de seu "Parmênides", portanto, na passagem da arte da caligrafia para a técnica da escrita maquinal.

espetaculosa voltada para o efeito. Após a segunda guerra, Heidegger dedica-se à noção do Gellasenheit, a "Serenidade", refletindo sobre a necessidade de uma meditação mais aprofundada sobre a relação ação e não-ação, atividade e passividade. Lembrando que Heidegger explica que não há uma representação mental, i.e., uma correspondência imediata para a palavra 'verdade' mas sentidos, cujo âmbito original ele localiza no movimento do descobrimento: "Verdade não é, jamais, "em si', apreensível por si, mas necessita ser ganha na luta" (HEIDEGGER, 2008, p. 35).

12 Heidegger define a obra de arte como o pôr-se em obra da verdade, confrontando a metafísica clássica e a tradição moderna da estética. "A arte não pergunta pelo fundamento daquilo que ela traz à tona, mas deixa que ele apareça 'sem quê nem porquê'. Arte não é conhecimento demonstrativo acerca dos entes em geral, mas repetição da própria gênese do horizonte de manifestação dos entes em sua unidade concreta de mundo e terra, campo de realização da reunião de cada coisa e de todas as coisas na tensão entre desvelamento e retração. Por meio da arte, portanto, Heidegger encontra uma via de acesso ao acontecimento apropriativo e à guarda do lugar mesmo de um tal acontecimento" (CASANOVA, 2009, p. 241).

CASANOVA, M. Antônio. Compreender Heidegger. Petrópolis: Vozes, 2009.

HEIDEGGER, Martin. Parmênides. Tradução de Sérgio Mário Wrublevski. Bragança Paulista/Petrópolis: Vozes, 2008. . Parmenides. Tradução de André Schuwer e Richard Rojcewicz. Bloomington e Indianapolis: Indiana University Press, 1992.

Ser e Tempo. Tradução de Márcia Sá C. Schuback.

\section{Referência Bibliográfica}

